\title{
Association between Meniere's disease and air pollution in South Korea
}

\author{
Dong-Han Lee ${ }^{1}$, Jiyeon Han ${ }^{2}$, Myoung-jin Jang2 ${ }^{2}$ Myung-Whan Suh ${ }^{3,4}$, Jun Ho Lee ${ }^{3,4}$, \\ Seung $\mathrm{HaOH}^{3,4}$ \& Moo Kyun Park ${ }^{3,4}$
}

Meniere's disease is thought to be a disorder of the inner ear function, affected by genetic and environmental factors. Several recent studies have shown that air pollution could affect middle and inner ear diseases. The purpose of this study was to investigate the relationship between the Meniere's disease occurrence and air pollution status in Korea. This study used a time-stratified casecrossover design. Hospital visit data by Meniere's disease were collected from the Korea National Health Insurance Service-National Sample Cohort (NHIS-NSC) database. Daily air pollution data for sulfur dioxide $\left(\mathrm{SO}_{2}\right)$, nitrogen dioxide $\left(\mathrm{NO}_{2}\right)$, carbon monoxide $(\mathrm{CO})$, ozone $\left(\mathrm{O}_{3}\right)$, and particulate matter $\left(\mathrm{PM}_{10}: \leq 10 \mu \mathrm{m}\right.$ in diameter, and $\mathrm{PM}_{2.5}: \leq 2.5 \mu \mathrm{m}$ in diameter) were collected from the National Ambient air quality Monitoring Information System (NAMIS) database. We used two-stage analysis to assess the association between degree of air pollution and the occurrence of Meniere's disease. In the first stage, region-specific analysis was conducted to estimate the odds ratios (ORs) of Meniere's disease risk associated with each air pollutant exposure by using conditional logistic regression for matched case-control sets in 16 regions. In the second stage, region-specific ORs from the first stage were combined and the pooled effect estimates were derived through fixed and random effect metaanalysis. Subgroup analysis was conducted for age, sex, seasonality, and urbanization of residence. In total, 29,646 (32.1\% males and 67.9\% females) Meniere's disease cases were identified from Korea NHIS-NSC database between 2008 and 2015. Overall, $\mathrm{SO}_{2}, \mathrm{NO}_{2}, \mathrm{CO}$, and $\mathrm{PM}_{10}$ showed significant correlation with Meniere's disease risk at immediate lags, and weaker correlation at delayed lags, whereas $\mathrm{O}_{3}$ showed slightly negative correlation at the immediate lag (lag0) and $\mathrm{PM}_{2.5}$ did not show strong correlation $\left(\mathrm{SO}_{2}: 1.04\right.$ [95\% confidence interval: 1.01, 1.06]; $\mathrm{NO}_{2}: 1.08$ [1.06, 1.11]; $\mathrm{CO}: 1.04$ $[1.02,1.06] ; \mathrm{O}_{3}: 0.96[0.93,0.99]$ : statistically significant $\mathrm{ORs}$ at lag0 are listed). These positive and negative associations between Meniere's disease and each air pollutant were generally stronger in the age of 40-64, female, summer (June-August) season, and urban subgroups. Our results showed that hospital visits for Meniere's disease were associated with the measured concentrations of ambient air pollutants $\mathrm{SO}_{2}, \mathrm{NO}_{2}, \mathrm{CO}$, and $\mathrm{PM}_{10}$. Further studies are required to confirm these associations and find their mechanisms.

Meniere's disease is a chronic illness of the inner ear characterized by episodic vertigo, fluctuating sensorineural hearing loss, ear fullness, and tinnitus, all of which decrease quality of life and could lead to permanent hearing loss. The annual incidence of Meniere's disease was estimated at around 8-400 per 100,000 in the early 2000s $\mathrm{s}^{1,2}$, and a recent study conducted in Korea reported similarly high values and a steep increase from 30.02 (in 2013) to 118.48 (in 2017) per $100,000^{3}$. According to a recent study in the UK, the annual health care costs associated with Meniere's disease were estimated between USD 829.9 and 934.2 million, equating to $\$ 5112-\$ 5748$ per person per year ${ }^{4}$.

Since it was first described in $1861^{5}$, Meniere's disease has been believed to be caused by the over-accumulation of endolymphatic fluid in the membranous labyrinth and subsequent membrane rupture ${ }^{6,7}$. Although several

\footnotetext{
${ }^{1}$ Department of Otorhinolaryngology-Head and Neck Surgery, Konkuk University Medical Center, Seoul, Republic of Korea. ${ }^{2}$ Medical Research Collaborating Center, Seoul National University Hospital, Seoul, South Korea. ${ }^{3}$ Department of Otorhinolaryngology-Head and Neck Surgery, Seoul National University College of Medicine, Seoul National University Hospital, 101 Daehak-ro Jongno-gu, Seoul 03080, Republic of Korea. ${ }^{4}$ Sensory Organ Research Institute, Seoul National University Medical Research Center, 101 Daehak-ro Jongno-gu, Seoul 03080, Republic of Korea. ${ }^{\varpi}$ email: entpmk@gmail.com
} 
etiologic factors such as anatomical and vestibular abnormalities, allergy, auto-immune disease, viral infection, and trauma are thought to be associated with Meniere's disease, its exact pathophysiology remains unclear ${ }^{8-10}$.

Diet, stress, and lifestyle are associated with the progress of Meniere's disease, and environmental factors such as atmospheric pressure and humidity are strongly related to the aggravation of Meniere's symptoms ${ }^{11}$, but the relationship between this disease and environmental pollution is not yet well known. Several recent studies have shown that environmental pollution affects middle and inner ear diseases ${ }^{12-15}$. Therefore, identifying the relationship between air pollution and Meniere's disease can help understand the pathophysiology of the disease and manage it.

The Korea National Health Insurance database provides health services with big data related to medical care, and we can integrate these data and air pollution data from the Korea Environment Corporation to analyze the association between the frequency of Meniere's disease hospital visits and the level of environmental pollution. The purpose of this study was to investigate the relationship between the Meniere's disease and air pollution.

\section{Patients and methods}

Database and study population. This study used data from the Korea National Health Insurance Service-National Sample Cohort (NHIS-NSC) database. All Korean people are given a unique registration number from birth and are obliged to join the NHIS, and all Korean hospitals use this identification number, so medical insurance claim records do not overlap and are not missing. The NHIS selected about $2 \%$ ( 1 million) of samples from the entire Korean population (50 million) and a previous study verified that these samples represented the entire population appropriately ${ }^{16}$. For each participant, this database contains comprehensive healthcare information including (1) patient information (sex, age, area of residence, and income level), (2) medical insurance claim codes (treatment procedures and prescriptions), (3) diagnostic codes in the format of the International Classification of Diseases-10 (ICD-10), (4) medical examination data, and (5) death records.

Study design. This study used a time-stratified case-crossover design, which was developed to study the effect of transient exposures on acute-onset events ${ }^{17,18}$. In the case-crossover design, each case's exposure prior to the event is compared to exposure in referent periods. In this way, each case serves as his or her own control, and time-invariant factors such as sex, ethnicity, and genetic background are automatically controlled. Furthermore, infrequently changing variables such as underlying chronic disease, socioeconomic status, area of residence, occupation, marriage status, seasonality, and age are also controlled by choosing control days close enough to the case day ${ }^{17,19-22}$.

Our hypothesis was that air pollution could trigger the onset of Meniere's disease. We selected the day of the insurance claim due to Meniere's disease as the case day. To avoid bias due to temporal variation or trend in exposures and to control for patterns in health care use depending on the day of the week, we selected control days in the same month and the same day of the week as the case day. Therefore, each case day had 3 or 4 control days for comparison. For example, if a subject visited the hospital due to Meniere's disease on a Monday in June 2010, all other Mondays in June 2010 were chosen as the control days, and the air pollution levels of the case day and control days were compared ${ }^{20}$.

This study was approved by the Seoul National University Hospital (SNUH) Institutional Review Board (IRB) (IRB No. 1806-001-948). All analyses were performed in accordance with relevant guidelines and regulations of the Ethics Committee of Seoul National University Hospital. Written informed consent was waived by the Institutional Review Board.

Participant selection and variables. In the NHIS-NSC data from February 2008 to December 2015, we traced a total of 882,230 individuals aged 19-79 to select subjects who visited hospitals (including emergency room visits and hospital admissions) for Meniere's disease (ICD-10 code H81.0) as the first-time diagnosis (without previous diagnosis with the same code during at least 1 year), to exclude regular follow-up visits without Meniere attack symptoms. From the selected participants, we collected the data on sex, age, date of hospital visit, and residence.

Air pollution data. Since April 2004, the Korea Environment Corporation has established the National Ambient air quality Monitoring Information System (NAMIS) to collect and manage air pollution data such as the levels of sulfur dioxide $\left(\mathrm{SO}_{2}\right)$, nitrogen dioxide $\left(\mathrm{NO}_{2}\right)$, carbon monoxide $(\mathrm{CO})$, ozone $\left(\mathrm{O}_{3}\right)$, and particulate matter $(\mathrm{PM})$ measured in air pollution measurement networks nationwide. Real-time concentrations of air pollutants are measured by automatic monitoring devices at 398 monitoring spots located in 112 areas (as of December 2018) all over the country. The NAMIS collects these data and provides them to the general public online (http://www.airkorea.or.kr). We used this database between January 1, 2008 and December 31, 2015.

We selected six pollutants that attract wide interest: (1) $\mathrm{SO}_{2}$ (measured by a pulse ultraviolet fluorescence method), (2) $\mathrm{NO}_{2}$ (by chemiluminescence), (3) $\mathrm{CO}$ (by a non-dispersive infrared method), (4) $\mathrm{O}_{3}$ (by an ultraviolet photometric method), (5) $\mathrm{PM}_{10}$ (PM $\leq 10 \mu \mathrm{m}$ in diameter; by a ray absorption method), and (6) $\mathrm{PM}_{2.5}$ $\left(\mathrm{PM} \leq 2.5 \mu \mathrm{m}\right.$ in diameter; by a ray absorption method). However, the data of $\mathrm{PM}_{2.5}$ were available only from 2015. For analysis, pollution information was classified into 16 regions on the basis of administrative districts.

Statistical analysis. The association between air pollution and the occurrence of Meniere's disease was examined via a two-stage analysis. In the first stage, the association in each region was estimated with the odds ratios (ORs) and 95\% confidence intervals (CIs) by using conditional logistic regression for matched case-control sets. In this analysis, the exposure to each air pollutant was fitted to a conditional logistic regression model using both the single lag structure (lag 0 , exposure on the case or control day; lag 1, 2, .., and 7; exposure 1, 2, 
$\ldots$, and 7 days prior to the case or control day) and cumulative lag structure (lag $0-1, \operatorname{lag} 0-2, \ldots$, and lag $0-7$; the moving average of exposure between the case or control day [0] and respective days prior to day 0 ) to consider the immediate, delayed, and cumulative effects of air pollution ${ }^{20}$. We analyzed the data using these various lag structures because we assumed that there may be a time interval between exposure to an air pollutant, the occurrence of Meniere's disease, and subsequent hospital visits. We included meteorological variables (temperature, rainfall, wind speed, and relative humidity) in the conditional logistic regression analysis; those variables were adjusted for the 4 day moving average (lag $0-3$ ) with a regression spline of 3 degrees and 4 knots for temperature to control for a possible non-linear association and with a linear term for the other variables ${ }^{20,23,24}$. All meteorological data were obtained from the Korea Meteorological Administration.

Subgroup analysis. We conducted region-specific subgroup analyses, which were stratified by potential effect modifiers such as age (three age groups: 19-39, 40-64, and 65-79 years), sex, and season (spring: March-May; summer: June-August, fall: September-November; winter: December-February) to find out the differences in Meniere's disease risk according to subgroup classification.

Joint-effect analysis. In addition, region-specific joint (combined) effects of multiple pollutants were analyzed by including multiple pollutants in the conditional logistic model in the following combinations: traffic gases $\left(\mathrm{NO}_{2}, \mathrm{CO}\right)$, oxidant gases $\left(\mathrm{SO}_{2}, \mathrm{NO}_{2}, \mathrm{O}_{3}\right)$, and criteria pollutants $\left(\mathrm{SO}_{2}, \mathrm{NO}_{2}, \mathrm{CO}, \mathrm{O}_{3}, \mathrm{PM}_{10}\right)^{25}$. Following the method of Winquist et al. ${ }^{25}$ a model including only individual pollutants of these combinations without interaction terms (non-interaction model) and a model including linear interaction terms were analyzed and compared. In the interaction model, the joint effects of the concentration change corresponding to the interquartile range (IQR) of each pollutant were calculated, starting at the 15th, 25th, and 35th percentile levels of each pollutant.

In the region-specific analysis, regions with small numbers of cases $(<20)$ were excluded because we failed to obtain results from data with a small number of cases in multivariable logistic models that included air pollutants and meteorological variables due to model convergence problem. In the analysis of association between $\mathrm{PM}_{2.5}$ and Meniere's disease, where only 2015 cases were used, one region (Chungnam) was excluded. In the subgroup analysis, six regions (Daejeon, Ulsan, Jeonbuk, Jeju, Chungnam, and Chungbuk) were excluded.

In the second stage, region-specific ORs from the first stage were combined and the pooled effect estimates were derived through fixed- and random-effect meta-analysis, which provided the overall effect of each pollutant on Meniere's disease throughout the regions as well as the regional variation of that effect. The results of the fixed-effect model were accepted when heterogeneity $\mathrm{I}^{2}$ was lower than $50 \%$, and the results of the random-effect model were accepted when $\mathrm{I}^{2}$ was higher than $50 \%{ }^{26}$. Additionally, pooled effect estimates were derived separately according to the grouping by urbanization of residence (urban or rural) to find out whether the occurrence of Meniere's disease is affected by urban and rural residence. Sixteen regions were classified into urban areas ( 1 special and 6 metropolitan cities: Seoul, Busan, Daegu, Incheon, Gwangju, Daejeon, and Ulsan) and rural areas (9 provinces: Gyeonggi, Ganwon, Chungbuk, Chungnam, Jeonbuk, Jeonnam, Gyeongbuk, Gyongnam, and Jeju) on the basis of administrative divisions.

All statistical analyses were conducted using SAS Enterprise Guide software (version 7.13; SAS Institute, Cary, NC, USA) and R: A Language and Environment for Statistical Computing (version 3.3.3; R Core Team, Vienna, Austria). All results were presented as estimated ORs and 95\% CIs per IQR increase at each air pollutant concentration ${ }^{20}$. IQR for each air pollutant was calculated from its 24-h average concentration in all regions as follows: $2.86 \mathrm{ppb}$ for $\mathrm{SO}_{2}, 12.52 \mathrm{ppb}$ for $\mathrm{NO}_{2}, 0.1 \mathrm{ppm}$ for $\mathrm{CO}, 16.3 \mathrm{ppb}$ for $\mathrm{O}_{3}, 27.19 \mu \mathrm{g} / \mathrm{m}^{3}$ for $\mathrm{PM}_{10}$, and $16.83 \mu \mathrm{g} / \mathrm{m}^{3}$ for $\mathrm{PM}_{2.5}$.

\section{Results}

Patient and air pollution distribution. In total, 29,646 (32.1\% males and 67.9\% females) Meniere's disease cases were identified from Korea NHIS-NSC database between 2008 and 2015; 4464 (33.6\% males and $66.4 \%$ females) cases were included in 2015 in the analysis of association with $\mathrm{PM}_{2.5}$, and 3972 (33.6\% males and $66.4 \%$ females) were included in the subgroup analysis of association with $\mathrm{PM}_{2.5}$ (Table 1). Among the three age groups, $40-64$ years was the largest ( $49.9 \%$ in 2008 to $2015,51.8 \%$ in 2015). The distribution of Meniere's disease did not differ significantly among seasons, but it occurred the least frequently in winter (23.1\% in 2008 to 2015 , $18.1 \%$ in 2015). The number of cases of Meniere's disease by region was from 438 (1.5\%) in Jeju to 5756 (19.4\%) in Gyeonggi (Table 2). Supplementary Table S1 shows the difference in air pollution levels and meteorological variables between the case and the control days at various lags. Except for $\mathrm{O}_{3}$, the concentrations of air pollutants were slightly higher on case days than on control days for most time delays, but no such tendency was found for most of meteorological variables. Supplementary Figure S1 shows weekly concentration of each air pollutant in a typical year (2015) when all pollutants were analyzed. There was noticeable concentration variability between adjacent weeks for all pollutants.

Association between air pollution and Meniere's disease. The final results of two-staged analysis are summarized in Fig. 1, which shows the pooled effect estimates that combine 16 region-specific estimates of Meniere's disease risk associated with an increase in IQR of each air pollutant according to various lag structures. Overall, $\mathrm{SO}_{2}, \mathrm{NO}_{2}, \mathrm{CO}$, and $\mathrm{PM}_{10}$ showed significant correlation with Meniere's disease risk at immediate lags, and weak correlation at delayed lags. $\mathrm{O}_{3}$ showed a slightly negative correlation at immediate lags, whereas $\mathrm{PM}_{2.5}$ showed no strong correlation. The estimated pooled effect ORs at lag0 were as follows: $\mathrm{SO}_{2}: 1.04$ (95\% CI 1.01, $1.06) ; \mathrm{NO}_{2}: 1.08$ (1.06, 1.11); CO: $1.04(1.02,1.06) ; \mathrm{O}_{3}: 0.96(0.93,0.99)$ (Supplementary Figure S2). 


\begin{tabular}{|c|c|c|c|c|}
\hline \multirow{2}{*}{$\begin{array}{l}\text { Study period: } \\
\text { Analysis: }\end{array}$} & \multicolumn{2}{|l|}{$2008-2015$} & \multicolumn{2}{|l|}{2015} \\
\hline & \multicolumn{2}{|c|}{$\begin{array}{l}\mathrm{SO}_{2}, \mathrm{NO}_{2}, \mathrm{CO}, \mathrm{O}_{3}, \\
\mathrm{PM}_{10}\end{array}$} & \multicolumn{2}{|l|}{$\mathrm{PM}_{2.5}{ }^{\mathrm{a}}$} \\
\hline Total & 29,646 (n) & $100(\%)$ & $3972(n)$ & $100(\%)$ \\
\hline \multicolumn{5}{|l|}{ Age } \\
\hline 19-39 & 6161 & 20.8 & 830 & 20.9 \\
\hline $40-64$ & 14,791 & 49.9 & 2058 & 51.8 \\
\hline $65-79$ & 8694 & 29.3 & 1084 & 27.3 \\
\hline \multicolumn{5}{|l|}{ Season $^{\mathrm{b}}$} \\
\hline Spring & 7585 & 25.6 & 1119 & 28.2 \\
\hline Summer & 7443 & 25.1 & 1043 & 26.3 \\
\hline Fall & 7769 & 26.2 & 1091 & 27.5 \\
\hline Winter & 6849 & 23.1 & 719 & 18.1 \\
\hline \multicolumn{5}{|l|}{ Sex } \\
\hline Male & 9519 & 32.1 & 1334 & 33.6 \\
\hline Female & 20,127 & 67.9 & 2638 & 66.4 \\
\hline
\end{tabular}

Table 1. Characteristics of 29,646 Meniere's disease cases according to subgroups in Korea between 2008 and 2015. ${ }^{a}$ In subgroup analysis for $\mathrm{PM}_{2.5}$, regions (Daejeon, Ulsan, Jeonbuk, Jeju, Chungnam, and Chungbuk) with fewer than 20 cases in the subgroup were excluded. ${ }^{b}$ Definitions for seasons are as follows: Spring (March-May), Summer (June-August), Fall (September-November), and Winter (December-February).

\begin{tabular}{|c|c|c|c|c|c|c|c|c|c|c|c|c|c|c|c|c|c|c|c|c|c|c|}
\hline \multirow{3}{*}{$\begin{array}{l}\begin{array}{l}\text { Study } \\
\text { period: }\end{array} \\
\text { Region }\end{array}$} & \multicolumn{3}{|c|}{ 2008-2015 } & \multirow{2}{*}{\multicolumn{3}{|c|}{$\begin{array}{l}2008-2015 \\
\begin{array}{l}\mathrm{SO}_{2} \text { percentiles } \\
(\mathrm{ppb})\end{array}\end{array}$}} & \multirow{2}{*}{\multicolumn{3}{|c|}{$\begin{array}{l}2008-2015 \\
\begin{array}{l}\mathrm{NO}_{2} \text { percentiles } \\
(\mathrm{ppb})\end{array}\end{array}$}} & \multirow{2}{*}{\multicolumn{3}{|c|}{$\begin{array}{l}2008-2015 \\
\begin{array}{l}\text { CO percentiles } \\
(0.1 \mathrm{ppm})\end{array}\end{array}$}} & \multirow{2}{*}{\multicolumn{3}{|c|}{$\begin{array}{l}2008-2015 \\
\begin{array}{l}\mathrm{O}_{3} \text { percentiles } \\
(\mathrm{ppb})\end{array}\end{array}$}} & \multirow{2}{*}{\multicolumn{3}{|c|}{$\begin{array}{l}2008-2015 \\
\mathrm{PM}_{10} \text { percentiles } \\
\left(\mu \mathrm{g} / \mathrm{m}^{3}\right)\end{array}$}} & \multirow{2}{*}{\multicolumn{3}{|c|}{$\begin{array}{l}2015^{\mathrm{a}} \\
\mathrm{PM}_{2.5} \text { percentiles ( } \\
\left.\mu \mathrm{g} / \mathrm{m}^{3}\right)\end{array}$}} & \multirow{3}{*}{$\begin{array}{l}2015^{\mathrm{a}} \\
\begin{array}{l}\text { Cases } \\
\text { of } \\
\text { MD }\end{array} \\
\text { (n) }\end{array}$} \\
\hline & \multirow{2}{*}{\begin{tabular}{l|}
$\begin{array}{l}\text { Cases } \\
\text { of } \\
\text { MD }\end{array}$ \\
$(n)$ \\
\end{tabular}} & \multirow{2}{*}{\begin{tabular}{|l}
$\begin{array}{l}\text { Sample } \\
\text { population }\end{array}$ \\
$(n)$ \\
\end{tabular}} & \multirow{2}{*}{$\begin{array}{l}\text { Incidence } \\
\text { per } 1000 \\
(n)\end{array}$} & & & & & & & & & & & & & & & & & & & \\
\hline & & & & 10 & 50 & 90 & 10 & 50 & 90 & 10 & 50 & 90 & 10 & 50 & 90 & 10 & 50 & 90 & 10 & 50 & 90 & \\
\hline Gangwon & 1280 & 33,008 & 38.78 & 1.6 & 2.9 & 6.9 & 8.1 & 13.0 & 21.6 & 3.2 & 4.9 & 8.5 & 17.1 & 27.2 & 45.3 & 20.4 & 41.4 & 76.0 & 10.5 & 22.3 & 45.7 & 241 \\
\hline Gyeonggi & 5756 & 245,245 & 23.47 & 3.2 & 4.9 & 7.9 & 16.2 & 27.3 & 44.3 & 3.7 & 5.2 & 8.5 & 9.2 & 21.3 & 38.2 & 25.4 & 49.9 & 89.3 & 9.8 & 22.2 & 45.2 & 1012 \\
\hline $\begin{array}{l}\text { Gyeong- } \\
\text { nam }\end{array}$ & 2080 & 66,927 & 31.08 & 2.6 & 4.0 & 6.3 & 9.6 & 16.1 & 28.0 & 2.8 & 4.0 & 6.1 & 15.4 & 27.8 & 43.2 & 25.0 & 42.0 & 72.7 & 12.5 & 24.0 & 38.7 & 345 \\
\hline $\begin{array}{l}\text { Gyeong- } \\
\text { buk }\end{array}$ & 1426 & 56,536 & 25.22 & 2.9 & 4.3 & 6.8 & 8.5 & 13.3 & 21.8 & 3.4 & 4.8 & 7.4 & 17.1 & 27.9 & 44.7 & 25.0 & 41.9 & 73.9 & 11.0 & 19.5 & 38.5 & 234 \\
\hline Gwangju & 1408 & 29,451 & 47.81 & 2.3 & 3.4 & 5.4 & 10.4 & 18.3 & 31.3 & 3.3 & 4.7 & 7.4 & 12.3 & 25.6 & 42.1 & 19.0 & 38.0 & 72.0 & 10.8 & 23.4 & 42.5 & 207 \\
\hline Daegu & 1299 & 50,343 & 25.80 & 2.3 & 3.9 & 7.6 & 11.7 & 21.1 & 38.6 & 2.9 & 4.5 & 7.3 & 9.4 & 23.3 & 41.9 & 23.3 & 42.5 & 77.0 & 10.5 & 22.4 & 40.1 & 232 \\
\hline Daejeon & 923 & 31,799 & 29.03 & 1.8 & 3.4 & 6.7 & 10.8 & 18.9 & 33.3 & 2.9 & 4.4 & 7.9 & 8.6 & 22.3 & 40.3 & 17.9 & 38.4 & 71.3 & 11.0 & 25.0 & 50.0 & 57 \\
\hline Busan & 1906 & 72,844 & 26.17 & 3.8 & 5.9 & 8.8 & 12.0 & 19.4 & 31.2 & 2.7 & 3.8 & 5.4 & 15.4 & 27.3 & 40.5 & 26.5 & 42.1 & 74.6 & 12.1 & 23.5 & 41.1 & 303 \\
\hline Seoul & 5186 & 222,083 & 23.35 & 3.4 & 4.9 & 7.8 & 18.7 & 31.7 & 51.2 & 3.4 & 4.9 & 8.5 & 7.2 & 19.8 & 36.3 & 19.4 & 42.0 & 79.3 & 9.9 & 20.8 & 38.8 & 819 \\
\hline Ulsan & 454 & 23,093 & 19.66 & 4.6 & 7.0 & 12.4 & 13.1 & 21.8 & 34.5 & 3.3 & 4.8 & 6.9 & 14.2 & 24.7 & 39.1 & 24.4 & 42.3 & 77.7 & 10.2 & 22.0 & 42.5 & 70 \\
\hline Incheon & 1470 & 59,747 & 24.60 & 4.2 & 6.1 & 9.6 & 13.6 & 23.7 & 40.7 & 3.6 & 5.2 & 8.6 & 12.8 & 25.6 & 41.3 & 24.9 & 46.3 & 84.3 & 11.9 & 24.9 & 49.5 & 261 \\
\hline Jeonnam & 2233 & 39,842 & 56.05 & 3.9 & 5.7 & 8.9 & 9.2 & 14.5 & 23.7 & 3.3 & 4.6 & 6.5 & 17.0 & 29.6 & 43.4 & 21.4 & 35.4 & 63.3 & 11.8 & 22.7 & 39.7 & 318 \\
\hline Jeonbuk & 1550 & 37,405 & 41.44 & 2.9 & 4.0 & 5.9 & 8.5 & 13.4 & 22.4 & 3.2 & 4.4 & 6.8 & 13.5 & 25.2 & 41.3 & 23.5 & 45.3 & 80.5 & 12.0 & 31.2 & 60.0 & 172 \\
\hline Jeju & 438 & 11,546 & 37.94 & 1.3 & 2.0 & 4.0 & 4.5 & 8.5 & 14.3 & 2.3 & 3.5 & 5.5 & 23.5 & 37.8 & 52.5 & 21.0 & 36.0 & 71.3 & 9.5 & 20.5 & 38.8 & 68 \\
\hline $\begin{array}{l}\text { Chung- } \\
\text { nam }\end{array}$ & 1281 & 45,833 & 27.95 & 2.3 & 3.7 & 6.2 & 8.6 & 14.1 & 23.6 & 3.4 & 4.8 & 7.7 & 15.7 & 28.0 & 43.7 & 20.6 & 40.5 & 73.6 & 11.0 & 23.0 & 44.0 & \\
\hline $\begin{array}{l}\text { Chung- } \\
\text { buk }\end{array}$ & 956 & 32,644 & 29.29 & 2.0 & 3.8 & 8.5 & 11.0 & 18.7 & 32.5 & 2.8 & 4.8 & 9.8 & 9.8 & 22.9 & 42.5 & 22.4 & 49.5 & 89.5 & 7.0 & 22.5 & 51.8 & 125 \\
\hline $\begin{array}{l}\text { All } \\
\text { regions }\end{array}$ & 29,646 & & & & & & & & & & & & & & & & & & & & & 4464 \\
\hline
\end{tabular}

Table 2. Regional Meniere's disease cases and air pollution distribution in Korea between 2008 and 2015. MD Meniere's disease. ${ }^{\mathrm{a}}$ In analysis for $\mathrm{PM}_{2.5}$, Chungnam region with fewer than 20 cases was excluded.

Analysis according to subgroups and potential effect modifiers. Figure 2 shows subgroup-specific estimated effects according to three age subgroups, sex, four seasons (spring, summer, fall, and winter), and urbanization of residence (urban or rural). Among the age subgroups, the correlation between air pollution and Meniere's disease risk was strongest at the age of 40-64, especially for $\mathrm{NO}_{2}, \mathrm{SO}_{2}$, and $\mathrm{CO} . \mathrm{O}_{3}$ showed a generally negative correlation in all age subgroups, and $\mathrm{PM}_{10}$ and $\mathrm{PM}_{2.5}$ showed no significant correlation in any age subgroup. Statistically significant results at lag0 were as follows: $\mathrm{SO}_{2}: 1.05(95 \% \mathrm{CI} 1.01,1.09)$ at age $40-64 ; \mathrm{NO}_{2}$ : 


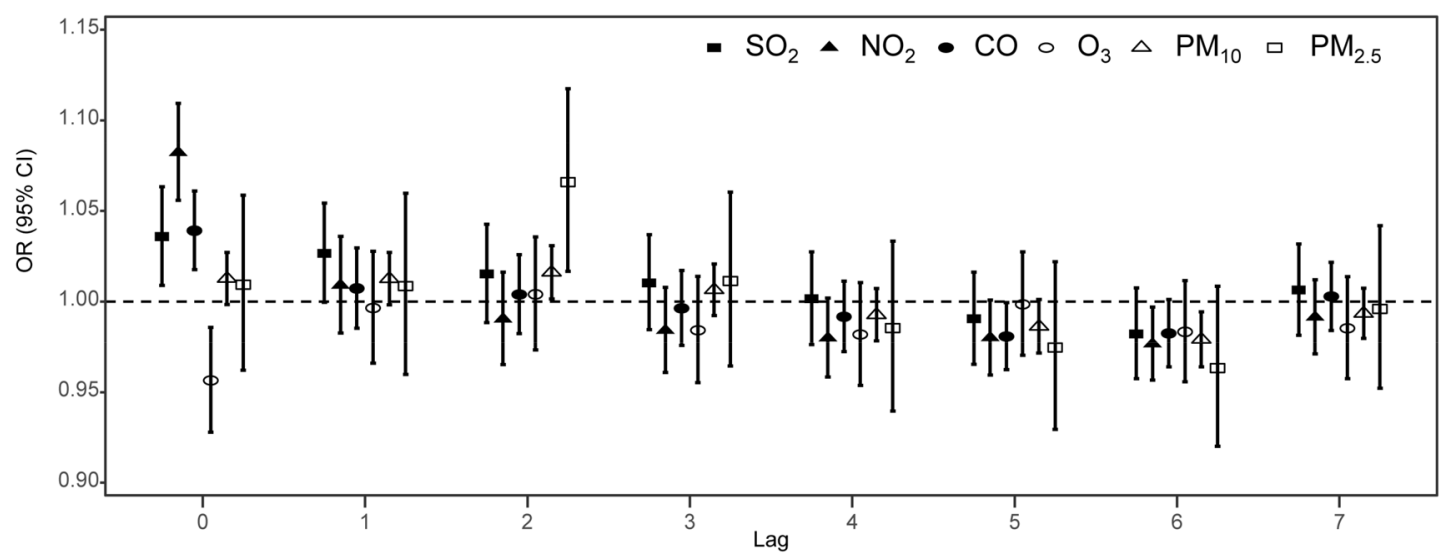

Cumulative lag

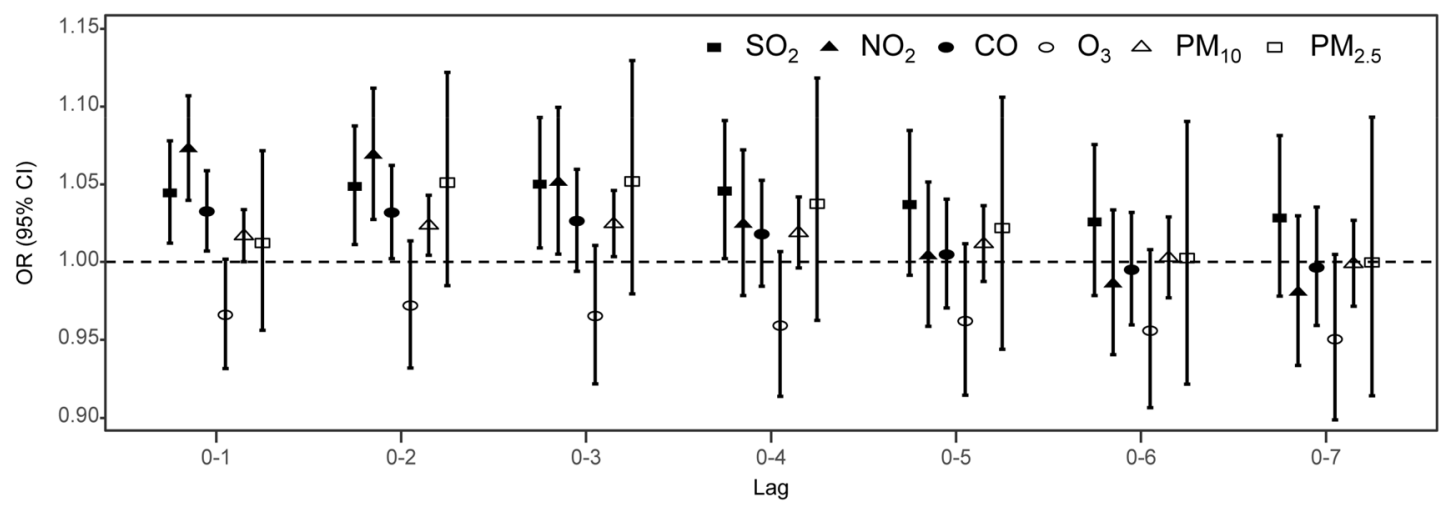

Figure 1. Association between Meniere's disease and air pollution. The pooled effect estimates of odd ratios (ORs) and 95\% CIs for Meniere's disease hospital visits considering interquartile range increase in each air pollutant concentration are presented according to various lag structures to take into account the immediate, delayed, and cumulative effects of air pollutants. Single lag indicates exposure on the case or control day (lag0) or on day 1-7 prior to the case or control day (lag1-lag7). Cumulative lag indicates the moving average of exposure between the case or control day and ' $n$ ' days prior to the case or control day (lag0-n). This figure was drawn using R: a Language and Environment for Statistical Computing (version 3.3.3; R Core Team, Vienna, Austria, https://www.R-project.org).

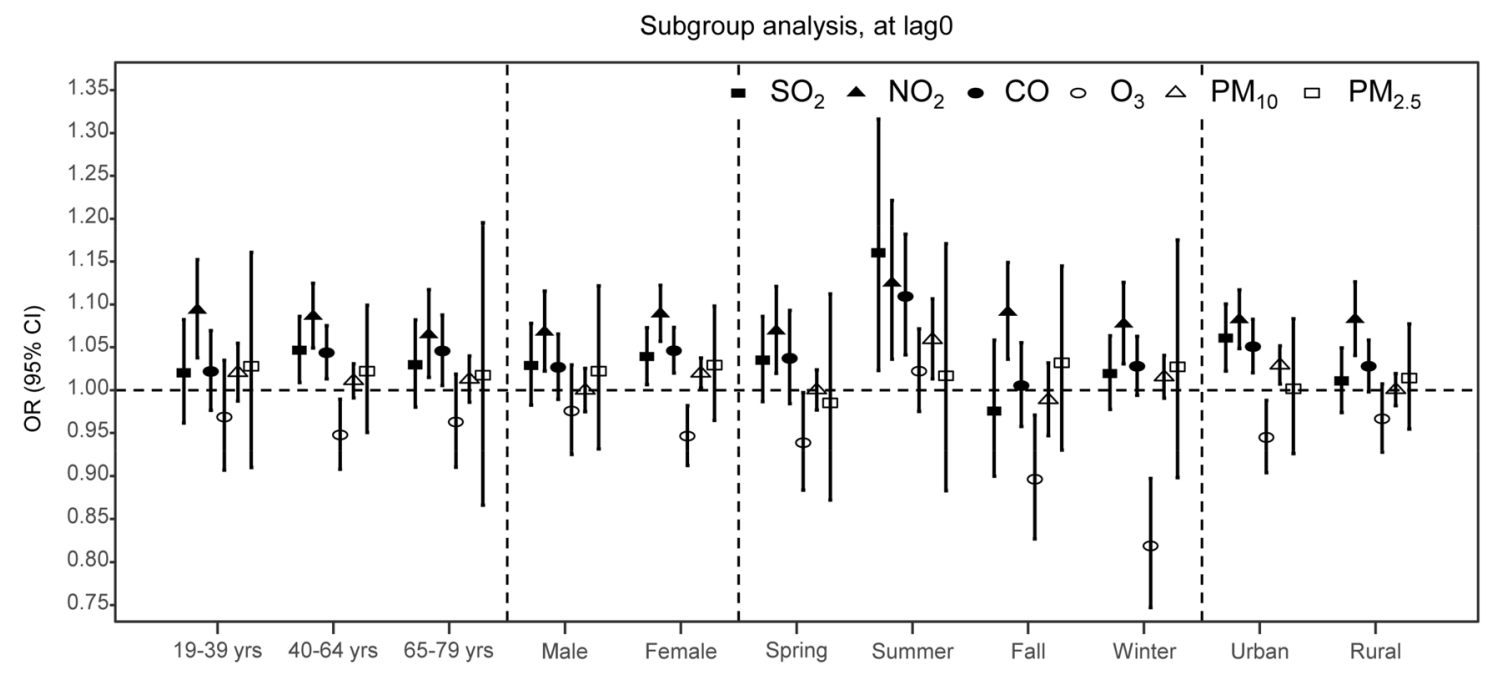

Figure 2. Subgroup analysis of association between Meniere's disease and air pollution. The pooled effect estimates of odd ratios (ORs) and 95\% CIs for Meniere's disease hospital visits considering interquartile range increase in each air pollutant concentration are presented according to subgroup (potential effect modifiers: age, sex, season, and urbanization of residence). This figure was drawn using R: a Language and Environment for Statistical Computing (version 3.3.3; R Core Team, Vienna, Austria, https://www.R-project.org). 


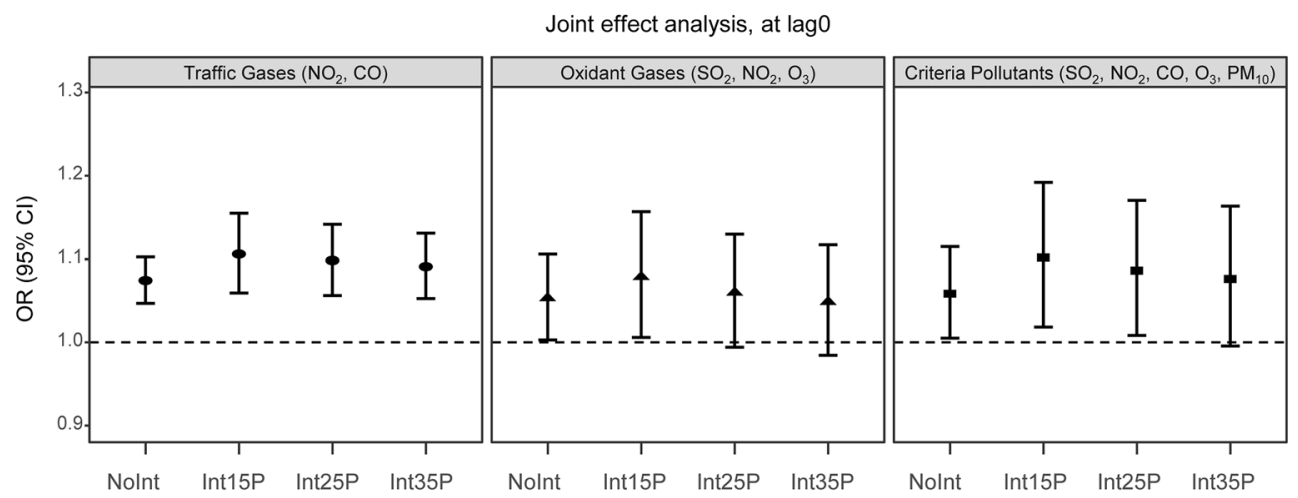

Figure 3. Joint effect of specific pollutant combinations for Meniere's disease. Joint effect estimates of odd ratios (ORs) and 95\% CIs for Meniere's disease hospital visits considering interquartile range (IQR) increase in concentrations of specific pollutant combinations on the case or control day (lag0) are presented using conditional logistic model including multiple pollutants with and without interactions. In the interaction models, the joint effects for the concentration change corresponding to the IQR were calculated, starting at the 15th, 25th, and 35th percentile level of each pollutant. This figure was drawn using R: a Language and Environment for Statistical Computing (version 3.3.3; R Core Team, Vienna, Austria, https://www.R-project. org). NoInt: No interactions; Int15P: interaction, starting at 15th percentile; Int25P: interaction, starting at 25th percentile; Int35P: interaction, starting at 35th percentile.

$1.09(1.04,1.15)$ at age $19-39,1.09(1.05,1.12)$ at age $40-64,1.06(1.01,1.12)$ at age $65-79 ;$ CO: $1.04(1.01,1.07)$ at age $40-64,1.05(1.01,1.09)$ at age $65-79 ; \mathrm{O}_{3}: 0.95(0.91,0.99)$ at age $40-64$.

These positive and negative associations between each air pollutant and Meniere's disease were more significant in women than in men in sex subgroup analysis, and $\mathrm{PM}_{10}$ in women (but not in men) showed significant association with Meniere disease risk at some lags. Statistically significant results at lag0 were as follows: $\mathrm{SO}_{2}$ : 1.04 (95\% CI 1.01, 1.07) in females; $\mathrm{NO}_{2}: 1.07(1.02,1.12)$ in males, $1.09(1.06,1.12)$ in females; CO: $1.05(1.02$, $1.07)$ in females; $\mathrm{O}_{3}: 0.95(0.91,0.98)$ in females.

Seasonal impact analysis showed a more significant correlation in summer than in the other seasons. Statistically significant results at lag0 were as follows: $\mathrm{SO}_{2}: 1.13(95 \% \mathrm{CI} 1.05,1.22)$ in summer; $\mathrm{NO}_{2}: 1.07(1.02,1.12)$ in spring, $1.12(1.04,1.22)$ in summer, $1.09(1.04,1.15)$ in fall, $1.08(1.03,1.13)$ in winter; CO: $1.11(1.04,1.18)$ in summer; $\mathrm{PM}_{10}: 1.06(1.01,1.11)$ in summer.

The effect of air pollution associated with Meniere's disease was more significant in urban than in rural areas. $\mathrm{SO}_{2}, \mathrm{NO}_{2}, \mathrm{CO}$, and $\mathrm{PM}_{10}$ at lag0, and $\mathrm{O}_{3}$ at lag0 showed significant negative correlation in urban areas. Statistically significant results at lag0 were as follows: $\mathrm{SO}_{2}: 1.06(95 \% \mathrm{CI} 1.02,1.10)$ in urban areas; $\mathrm{NO}_{2}: 1.08(1.05,1.12)$ in urban areas, $1.08(1.04,1.13)$ in rural areas; $\mathrm{CO}: 1.05(1.02,1.08)$ in urban areas; $\mathrm{O}_{3}: 0.94(0.90,0.99)$ in urban areas; $\mathrm{PM}_{10}: 1.03(1.01,1.05)$ in urban areas.

Joint-effect analysis. Joint-effect analysis showed that increases in the concentrations of all pollutant combinations investigated were associated with increases in Meniere's disease hospital visits (Fig. 3). The pooled estimated ORs at lag0 for the joint effect by an IQR increase in the non-interaction model were as follows: traffic gases $\left(\mathrm{NO}_{2}, \mathrm{CO}\right): 1.07$ (95\% CI 1.05, 1.10) and criteria pollutants $\left(\mathrm{SO}_{2}, \mathrm{NO}_{2}, \mathrm{CO}, \mathrm{O}_{3}, \mathrm{PM}_{10}\right): 1.06(1.01,1.11)$. The joint-effect estimates in the interaction model were as follows: traffic gases: $1.11(95 \%$ CI 1.06, 1.15) when starting at the 15 th percentile, $1.10(1.06,1.14)$ when starting at the 25 th percentile, $1.09(1.05,1.13)$ when starting at the 35th percentile; oxidant gases $\left(\mathrm{SO}_{2}, \mathrm{NO}_{2}, \mathrm{O}_{3}\right): 1.08(1.01,1.16)$ when starting at the 15th percentile; criteria pollutants: $1.10(1.02,1.19)$ when starting at the 15 th percentile, $1.09(1.01,1.17)$ when starting at the 25 th percentile. Compared to the non-interaction model, the estimated joint effects of the interaction model were slightly larger or similar.

\section{Discussion}

Meniere's disease is generally hypothesized to be caused by endolymphatic hydrops, but there are still debates on the exact pathophysiologic mechanism ${ }^{27}$. Although endolymphatic hydrops is identified in most Meniere patients, animal models with induced endolymphatic hydrops have failed to develop the characteristic attacks with Meniere-like symptoms ${ }^{28-30}$. In addition, there are patients with endolymphatic hydrops without Meniere symptoms ${ }^{31,32}$. Conversely, there are patients with Meniere symptoms but without any sign of endolymphatic hydrops in temporal bone histopathology ${ }^{31,32}$. Anatomical variances such as short and narrow vestibular aqueduct found in Meniere's patients are thought to cause endolymphatic hydrops ${ }^{33-35}$. The elevated serum levels of immune mediators in Meniere patients suggest that Meniere's disease may be related to allergies or immunologic factors $^{36-46}$. Clinical features and its course, MR imaging, and serological and epidemiologic evidence support the viral etiology of Meniere's disease, and histopathologic analysis also suggests viral infection as a causative factor for structural abnormalities of the endolymphatic duct and $\operatorname{sac}^{47-52}$.

Extensive efforts have been made to find an effective management and treatment for Meniere's disease, and to understand its pathophysiologic mechanism. Traditional treatment strategies for Meniere's disease include life 
style modification (e.g., stress relief, getting enough sleep, and avoiding alcohol and smoking) ) $^{53}$, diet therapy (e.g., low salt $\operatorname{diet}^{54}$, high water intake ${ }^{53,54}$, and limitation of caffeine), medication (e.g., diuretics ${ }^{54-57}$, betahistine b $^{55,58-60}$, intratympanic corticosteroids ${ }^{9,61-63}$, and intratympanic gentamycin ${ }^{64,65}$ ), and surgery (e.g., ventilation tube insertion with or without middle ear pressure application ${ }^{6-69}$, endolymphatic sac decompression ${ }^{70}$, and although destructive, vestibular neurectomy or labyrinthectomy in selected intractable cases ${ }^{71}$ ). However, due to the lack of well-designed randomized controlled trials, the evidence for these treatment strategies is still weak.

Several studies have suggested that environmental pollution could be associated with inner ear problems ${ }^{72}$. In 2012, studies that analyzed the data from the U.S. National Health and Nutritional Examination Survey (NHANES) showed that exposure to cadmium and lead might be associated with hearing loss ${ }^{73}$ and vestibular dysfunction ${ }^{74}$. Some studies have suggested an association between environmental pollution and middle ear disease such as otitis media ${ }^{75-77}$. Therefore, we hypothesized that Meniere's disease, which is believed to be caused by physiological dysfunction of the inner ear, may also be affected by environmental pollution. In 2017, Han and colleagues analyzed the NHIS-NSC data and reported that hospital visits due to Meniere's disease were associated with environmental PM exposure, especially in the elderly ${ }^{12}$. However, among various air pollutants, this study analyzed only $\mathrm{PM}_{10}$ and $\mathrm{PM}_{2.5}$ in only one city, Seoul. Similar to this study, we also used time-stratified case-crossover analysis, which is thought to be an effective epidemiologic tool for assessing the triggering factor of a disease, but we included many more pollutants and regions in the analysis.

Our analysis suggests a possible association between the onset of Meniere's disease and concentration of air pollutants such as $\mathrm{SO}_{2}, \mathrm{NO}_{2}$, and $\mathrm{CO}$, as well as $\mathrm{PM}_{10}$ and $\mathrm{PM}_{2.5}$. Our joint-effect analysis also shows that specific air pollutant mixtures such as traffic gases $\left(\mathrm{NO}_{2}, \mathrm{CO}\right)$, oxidant gases $\left(\mathrm{SO}_{2}, \mathrm{NO}_{2}, \mathrm{O}_{3}\right)$, and criteria pollutants $\left(\mathrm{SO}_{2}\right.$, $\mathrm{NO}_{2}, \mathrm{CO}, \mathrm{O}_{3}, \mathrm{PM}_{10}$ ) may be associated with the onset of Meniere's disease. Air pollution can induce allergic reaction or systemic inflammation ${ }^{78}$, and this inflammation could affect the inner ear physiology. On the other hand, inflammation caused by air pollution can cause psychological distress symptoms ${ }^{79}$. In 2004, Söderman et al. reported that prior emotional stress could affect the Meniere's attack ${ }^{80}$. In 2012, Lim et al. reported that air pollutants such as $\mathrm{PM}_{10}, \mathrm{NO}_{2}$, and $\mathrm{O}_{3}$ may increase depressive symptoms in the elderly ${ }^{81}$. Many other reports show the association between air pollution and headache and migraine symptoms, which are commonly cooccurring symptoms in Meniere patients ${ }^{82-84}$. These findings may be related to each other and provide a clue to how air pollution causes Meniere's disease.

Our subgroup analysis showed that the correlation between air pollution and Meniere's disease risk was strongest in the age of 40-64, female, and summer (June-August) season subgroups. Meniere's disease is known to be more common in middle-aged adults than in children or the elderly ${ }^{85}$, and more common in women than in men $^{2,86}$. In 2017, Schmidt et al. reported that weather conditions such as low atmospheric pressure and high humidity are associated with Meniere's attacks ${ }^{11}$. Therefore, a possible interpretation of this result is that air pollution may have a synergetic effect in these subgroups. We found a more significant association in urban than in rural areas, but this association was weaker than we expected. As in a previous study conducted in Korea ${ }^{15}$, we grouped 16 regions into urban and rural on the basis of administrative divisions, but the concentration of pollutants in urban areas was not necessarily higher than in rural areas, probably because industrial facilities or plants are distributed in some rural areas.

Interestingly, we observed a generally negative association between $\mathrm{O}_{3}$ level and onset of Meniere's disease, although ozone is a toxic gas and no beneficial effects of ground-level ozone on human health are known. A possible interpretation is that this negative association is partially due to a coincidental negative correlation of $\mathrm{O}_{3}$ with other pollutants. In our study, Spearman correlation coefficient Rho was -0.18 for $\mathrm{O}_{3}$ and $\mathrm{SO}_{2},-0.29$ for $\mathrm{O}_{3}$ and $\mathrm{CO}$, and -0.40 for $\mathrm{O}_{3}$ and $\mathrm{NO}_{2}$. Previous studies have also reported negative correlation between $\mathrm{O}_{3}$ and other pollutants ${ }^{78,87-89}$. In a study that assessed the association between air pollution and suicide risk, $\mathrm{O}_{3}$ levels were less associated with suicide risk than those of other pollutants such as $\mathrm{SO}_{2}, \mathrm{NO}_{2}, \mathrm{CO}$, and $\mathrm{PM}_{10}{ }^{20}$. However, there is a lack of evidence that $\mathrm{O}_{3}$ is always negatively correlated with other pollutants. $\mathrm{CO}, \mathrm{NO}_{2}$, and $\mathrm{PM}$ are produced mainly by automobiles, and $\mathrm{SO}_{2}$ is produced by combustion of coal and sulfur-containing fossil fuels, but ground-level $\mathrm{O}_{3}$ is typically produced from nitrogen oxides and volatile organic compounds by photochemical reactions that require heat and sunlight, so the $\mathrm{O}_{3}$ level is high in summer ${ }^{90}$. Another possible interpretation is that this negative correlation may be due to reduced outdoor activity in extreme weather conditions, when high temperatures and sunlight result in high $\mathrm{O}_{3}$ levels ${ }^{20}$. At this moment, it is unclear whether $\mathrm{O}_{3}$ has a direct impact on Meniere's disease.

Contrary to our expectation, we found no significant association between $\mathrm{PM}_{2.5}$ and Meniere's disease, possible because of insufficient sample size for $\mathrm{PM}_{2.5}$. The data for $\mathrm{PM}_{2.5}$ were available only for 2015, and many regions were excluded from the subgroup analysis due to a statistical processing problem. Since various factors may affect the onset of Meniere's disease, we think that it is difficult to demonstrate the effects of ambient air pollutants that are present in small amounts in the atmosphere if we do not have enough samples.

Several limitations should be considered in the interpretation of the results of this study. The data on the occurrence of Meniere's disease we collected might differ from reality. The diagnosis of Meniere's disease was not confirmed pathologically in clinical settings and was based on clinical symptoms. The diagnostic criteria of individual clinicians might not be identical, and because the data on the occurrence of Meniere's disease were based on the insurance claim code, the occurrence might have been underestimated, which is a fundamental limitation of this type of research. In addition, there could be a time difference between exposure to air pollution, the occurrence of Meniere's disease, and the resulting hospital visits, so we analyzed the data using various lag structures, but there might be a lag heterogeneity for each individual. However, we believe that the delay between the patient's symptoms and the visit to the hospital would not have been very long. To collect the data on the first or acute attack of Meniere's disease and exclude regular visits, we selected patients who had not been diagnosed with the same code in the previous year, and included emergency room visits and hospital admissions. Generally, the more pronounced the discomfort symptoms are, the more likely the hospital visit will be made immediately 
rather than delayed. If a clinician made a diagnosis under the exact insurance claim code of Meniere's disease, we assume that the symptoms would have been clear enough for diagnosis. Korea is relatively small in terms of land area, and most of the population is concentrated in urban areas, so patients have good geographical access to hospitals. As the NHIS covers the entire Korean population and medical fees are low, the threshold for the use of medical care is also low ${ }^{91}$. Given that, in the majority of cases it can be assumed that the patient's visit to the hospital was not considerably delayed. Another limitation is that air pollution was measured at specific locations in each city and the average was taken, and since our study did not take into account the actual time of the individual's outdoor activities during the day, the individual's actual pollutant exposure might not be precisely reflected. Also, several confounding factors such as sleep quality, stress, diet, and symptom severity were not considered in the analysis because of to the lack of data. In addition, our interpretations may be applicable only to the Korean region because inter-regional differences in environmental conditions and ethnicities may affect the results of analysis.

Although the interpretation of our results may be controversial, we have identified a possible association between air pollution and the occurrence of Meniere's disease. But the mechanism by which air pollution affects Meniere disease is still unclear. Therefore, further animal study or well controlled prospective study is needed to support our interpretations of the data.

\section{Conclusion}

Our time-stratified case-crossover analysis showed that Meniere's disease hospital visits were associated with the measured concentrations of ambient air pollutants such as $\mathrm{SO}_{2}, \mathrm{NO}_{2}, \mathrm{CO}$, and $\mathrm{PM}_{10}$. This association was stronger in the age of 40-64, female, summer (June-August) season, and urban subgroups. Further studies are needed to confirm these associations and determine their mechanisms.

\section{Data availability}

All the data used in this study are available from the Korea National Health Insurance Service-National Sample Cohort (NHIS-NSC) database, Korea National Ambient air quality Monitoring Information System (NAMIS) database, and the Korea Meteorological Administration database.

Received: 25 January 2021; Accepted: 2 June 2021

Published online: 23 June 2021

\section{References}

1. Sajjadi, H. \& Paparella, M. M. Meniere's disease. Lancet (Lond., Engl.) 372, 406-414. https://doi.org/10.1016/s0140-6736(08)61161-7 (2008).

2. Ballester, M., Liard, P., Vibert, D. \& Häusler, R. Menière's disease in the elderly. Otol. Neurotol. 23, 20 (2002).

3. Kim, M. H. \& Cheon, C. Epidemiology and seasonal variation of Ménière's disease: Data from a population-based study. Audiol. Neurotol. 20, 1-7 (2020).

4. Tyrrell, J., Whinney, D. J. \& Taylor, T. The cost of Ménière’s disease: A novel multisource approach. Ear Hear. 37, e202-e209 (2016).

5. Méniere, P. Lectures-Maladie de L'oreille. Sur une forme particuliere de surdite grave dependent d'une lesion de l'oreille interna. Gaz. Med. Ser. 16, 29 (1861).

6. Schuknecht, H. Pathology of the Ear, Vol. 273 2nd edn. (Lea \& Febiger, 1993).

7. Brown, D. H., Mcclure, J. A. \& Downar-Zapolski, Z. The membrane rupture theory of Meniere's disease-is it valid?. Laryngoscope 98, 599-601 (1988).

8. Kiang, N. An Auditory Physiologist's View of MÉNIĖRE'S Syndrome. Meniere's Disease 13-24 (Kugler Publications, 1989).

9. Minor, L. B., Schessel, D. A. \& Carey, J. P. Meniere's disease. Curr. Opin. Neurol. 17, 9-16 (2004).

10. Baloh, R. W. Prosper Meniere and his disease. Arch. Neurol. 58, 1151-1156 (2001).

11. Schmidt, W. et al. The weather and Ménière's disease: A longitudinal analysis in the UK. Otol. Neurotol. 38, 225-233. https://doi. org/10.1097/MAO.0000000000001270 (2017).

12. Han, C., Lim, Y. H., Jung, K. \& Hong, Y. C. Association between ambient particulate matter and disorders of vestibular function. Environ. Res. 155, 242-248. https://doi.org/10.1016/j.envres.2017.02.013 (2017).

13. Lee, H. M. et al. Effects of meteorological factor and air pollution on sudden sensorineural hearing loss using the health claims data in Busan, Republic of Korea. Am. J. Otolaryngol. 40, 393-399. https://doi.org/10.1016/j.amjoto.2019.02.010 (2019).

14. Chang, K. H. et al. Increased risk of sensorineural hearing loss as a result of exposure to air pollution. Int. J. Environ. Res. Public Health 17, 20. https://doi.org/10.3390/ijerph17061969 (2020).

15. Choi, H. G., Min, C. \& Kim, S. Y. Air pollution increases the risk of SSNHL: A nested case-control study using meteorological data and national sample cohort data. Sci. Rep. 9, 1-8 (2019).

16. Lee, J., Lee, J. S., Park, S. H., Shin, S. A. \& Kim, K. Cohort profile: The national health insurance service-national sample cohort (NHIS-NSC), South Korea. Int. J. Epidemiol. 46, E15. https://doi.org/10.1093/ije/dyv319 (2017).

17. Levy, D., Lumley, T., Sheppard, L., Kaufman, J. \& Checkoway, H. Referent selection in case-crossover analyses of acute health effects of air pollution. Epidemiology 12, 186-192 (2001).

18. Maclure, M. The case-crossover design: A method for studying transient effects on the risk of acute events. Am. J. Epidemiol. 133, 144-153 (1991).

19. Zanobetti, A. \& Schwartz, J. The effect of particulate air pollution on emergency admissions for myocardial infarction: A multicity case-crossover analysis. Environ. Health Perspect. 113, 978-982 (2005).

20. Lee, H., Myung, W., Kim, S. E., Kim, D. K. \& Kim, H. Ambient air pollution and completed suicide in 26 South Korean cities: Effect modification by demographic and socioeconomic factors. Sci. Total Environ. 639, 944-951. https://doi.org/10.1016/j.scito tenv.2018.05.210 (2018).

21. Schwartz, J., Zanobetti, A. \& Bateson, T. Morbidity and mortality among elderly residents in cities with daily PM measurements. Revised Anal. Time Ser. Stud. Air Pollut. Health 20, 25-58 (2003).

22. Janes, H., Sheppard, L. \& Lumley, T. Case-crossover analyses of air pollution exposure data: Referent selection strategies and their implications for bias. Epidemiology 20, 717-726 (2005).

23. Bakian, A. V. et al. Acute air pollution exposure and risk of suicide completion. Am. J. Epidemiol. 181, 295-303 (2015).

24. Kim, C. et al. Ambient particulate matter as a risk factor for suicide. Am. J. Psychiatry 167, 1100-1107 (2010). 
25. Winquist, A. et al. Joint effects of ambient air pollutants on pediatric asthma emergency department visits in Atlanta, 1998-2004. Epidemiology (Camb., Mass.) 25, 666 (2014).

26. Higgins, J. P., Thompson, S. G., Deeks, J. J. \& Altman, D. G. Measuring inconsistency in meta-analyses. BMJ 327, 557-560 (2003).

27. Gibson, W. P. R. Meniere's disease. Adv. Otorhinolaryngol. 82, 77-86. https://doi.org/10.1159/000490274 (2019).

28. Kimura, R. S. LII experimental blockage of the endolymphatic DUCT and SAC and ITS effect on the inner ear of the guinea pig: A study on endolymphatic hydrops. Ann. Otol. Rhinol. Laryngol. 76, 664-687 (1967).

29. Warmerdam, T., Schröder, F., Wit, H. \& Albers, F. Perilymphatic and endolymphatic pressure in the guinea pig after distal dissection of the endolymphatic sac. Otol. Neurotol. 22, 373-376 (2001).

30. Valk, W., Wit, H. \& Albers, F. Rupture of Reissner's membrane during acute endolymphatic hydrops in the guinea pig: A model for Meniere's disease?. Acta Otolaryngol. 126, 1030-1035 (2006).

31. Merchant, S. N., Adams, J. C. \& Nadol, J. B. Jr. Pathophysiology of Meniere's syndrome: Are symptoms caused by endolymphatic hydrops?. Otol. Neurotol. 26, 74-81 (2005).

32. Vasama, J.-P. \& Linthicum, F. H. Jr. Meniere's disease and endolymphatic hydrops without Meniere's symptoms: Temporal bone histopathology. Acta Otolaryngol. 119, 297-301 (1999).

33. Shea, J. J. Jr., Ge, X., Warner, R. M. \& Orchik, D. J. External aperture of the vestibular aqueduct in Meniere’s disease. Otol. Neurotol. 21, 351-355 (2000).

34. Valvassori, G. E. \& Dobben, G. D. Multidirectional and computerized tomography of the vestibular aqueduct in Meniere's disease. Ann. Otol. Rhinol. Laryngol. 93, 547-550 (1984).

35. Hebbar, G. K., Rask-Andersen, H. \& Linthicum, F. H. Jr. Three-dimensional analysis of 61 human endolymphatic ducts and sacs in ears with and without Meniere's disease. Ann. Otol. Rhinol. Laryngol. 100, 219-225 (1991).

36. Broughton, S. S., Meyerhoff, W. E. \& Cohen, S. B. Immune-mediated inner ear disease: 10-year experience. Semin. Arthritis Rheum. 34, 544-548. https://doi.org/10.1016/j.semarthrit.2004.07.001 (2004).

37. Cisi, E. D., Moreira Bittar, R. S. \& FerreiradeMello, J. Jr. Hypersensitivity to inhalants and food in balance disturbances. Revue Laryngol. Otol. Rhinol. 132, 81-84 (2011).

38. Duke, W. Meniere's syndrome caused by allergy. J. Am. Med. Assoc. 81, 2179-2181 (1923).

39. McCabe, B. Autoimmune sensorineural hearing loss. 1979. Ann. Otol. Rhinol. Laryngol. 113, 526 (2004).

40. Brookes, G. B. Circulating immune complexes in Meniere's disease. Arch. Otolaryngol. Head Neck Surg. 112, 536-540 (1986).

41. Yoo, T. et al. Type II collagen autoimmunity in otosclerosis and Meniere's disease. Science 217, 1153-1155 (1982).

42. Greco, A. et al. Meniere's disease might be an autoimmune condition?. Autoimmun. Rev. 11, 731-738 (2012).

43. Derebery, M. J. \& Berliner, K. I. Prevalence of allergy in Meniere's disease. Otolaryngol. Head Neck Surg. 123, 69-75 (2000).

44. Rask-Andersen, H. \& Stahle, J. Immunodefence of the inner ear?: Lymphocyte-macrophage interaction in the endolymphatic sac. Acta Otolaryngol. 89, 283-294 (1980).

45. Arnold, W., Altermatt, H. \& Gebbers, J. Qualitative detection of immunoglobulins in the human endolymphatic sac. Laryngol. Rhinol. Otol. 63, 464 (1984).

46. Harris, J. P. Immunology of the inner ear: Evidence of local antibody production. Ann. Otol. Rhinol. Laryngol. 93, 157-162 (1984).

47. Arnold, W. \& Niedermeyer, H. P. Herpes simplex virus antibodies in the perilymph of patients with Meniere disease. Arch. Otolaryngol. Head Neck Surg. 123, 53-56 (1997).

48. Shambaugh, G. E., Clemis, J. D. \& Arenberg, I. K. Endolymphatic duct and sac in Meniere’s disease. Arch. Otolaryngol. 89, 816-825 (1969).

49. Arenberg, I. K., Lemke, C. \& Shambaugh, G. E. Jr. Viral theory for Meniere's disease and endolymphatic hydrops: Overview and new therapeutic options for viral labyrinthitis. Ann. N. Y. Acad. Sci. 830, 306-313 (1997).

50. Furuta, Y. et al. Latent herpes simplex virus type 1 in human geniculate ganglia. Acta Neuropathol. 84, 39-44 (1992).

51. Calenoff, E. et al. Patients with Meniere's disease possess IgE reacting with herpes family viruses. Arch. Otolaryngol. Head Neck Surg. 121, 861-864 (1995).

52. Gacek, R. R. \& Gacek, M. R. Menière’s disease as a manifestation of vestibular ganglionitis. Am. J. Otolaryngol. 22, 241-250 (2001).

53. Naganuma, H., Kawahara, K., Tokumasu, K. \& Okamoto, M. Water may cure patients with Meniere disease. Laryngoscope 116, 1455-1460 (2006)

54. Thai-Van, H., Bounaix, M.-J. \& Fraysse, B. Ménière’s disease. Drugs 61, 1089-1102 (2001).

55. Claes, J. \& Van de Heyning, P. Medical treatment of Meniere's disease: A review of literature. Acta Otolaryngol. 117, 37-42 (1997).

56. Corvera, J. \& Corvera, G. Long-term effect of acetazolamide and chlorthalidone on the hearing loss of Menière's disease. Am. J. Otol. 10, 142-145 (1989).

57. Thirlwall, A. \& Kundu, S. Diuretics for Meniere's disease or syndrome. Cochrane Database Syst. Rev. 3, CD003599 (2006).

58. Oosterveld, W. Betahistine dihydrochloride in the treatment of vertigo of peripheral vestibular origin. J. Laryngol. Otol. 98, 37-41 (1984).

59. Hommes, O. A study of the efficacy of betahistine in Meniere's syndrome. Acta Otolaryngol. 74, 70-79 (1972).

60. James, A. \& Burton, M. J. Betahistine for Meniere's disease or syndrome. Cochrane Database Syst. Rev. 20, 20 (2001).

61. Shea, J. J. The role of dexamethasone or streptomycin perfusion in the treatment of Meniere's disease. Otolaryngol. Clin. North Am. 30, 1051-1059 (1997).

62. Garduño-Anaya, M. A., De Toledo, H. C., Hinojosa-González, R., Pane-Pianese, C. \& Ríos-Castañeda, L. C. Dexamethasone inner ear perfusion by intratympanic injection in unilateral Meniere's disease: A two-year prospective, placebo-controlled, double-blind, randomized trial. Otolaryngol. Head Neck Surg. 133, 285-294 (2005).

63. Phillips, J. S. \& Westerberg, B. Intratympanic steroids for Meniere's disease or syndrome. Cochrane Database Syst. Rev. 20, 20 (2011).

64. Pullens, B. \& van Benthem, P. P. Intratympanic gentamicin for Meniere's disease or syndrome. Cochrane Database Syst. Rev. 20, 20 (2011).

65. Chia, S. H., Gamst, A. C., Anderson, J. P. \& Harris, J. P. Intratympanic gentamicin therapy for Meniere's disease: A meta-analysis. Otol. Neurotol. 25, 544-552 (2004).

66. Sass, K. \& Densert, B. Control of symptoms in patients with Meniere's disease using middle ear pressure applications: Two years follow-up. Acta Otolaryngol. 121, 616-621 (2001).

67. Barbara, C. C. et al. Local pressure protocol, including Meniett, in the treatment of Meniere's disease: Short-term results during the active stage. Acta Oto-laryngol. 121, 939-944 (2001).

68. Gates, G. A., Verrall, A., Green, J. D., Tucci, D. L. \& Telian, S. A. Meniett clinical trial: Long-term follow-up. Arch. Otolaryngol. Head Neck Surg. 132, 1311-1316 (2006).

69. Thomsen, J., Sass, K., Ödkvist, L. \& Arlinger, S. Local overpressure treatment reduces vestibular symptoms in patients with Meniere’s disease: A clinical, randomized, multicenter, double-blind, placebo-controlled study. Otol. Neurotol. 26, 68-73 (2005).

70. Pullens, B., Verschuur, H. P. \& van Benthem, P. P. Surgery for Ménière’s disease. Cochrane Database Syst. Rev. 20, 20 (2013).

71. McKee, G., Kerr, A., Toner, J. \& Smyth, G. Surgical control of vertigo in Meniere’s disease. Clin. Otolaryngol. Allied Sci. 16, 216-227 (1991).

72. Campo, P., Morata, T. C. \& Hong, O. Chemical exposure and hearing loss. Dis. Month 59, 119 (2013).

73. Choi, Y.-H., Hu, H., Mukherjee, B., Miller, J. \& Park, S. K. Environmental cadmium and lead exposures and hearing loss in US adults: The National Health and Nutrition Examination Survey, 1999 to 2004. Environ. Health Perspect. 120, 1544-1550 (2012). 
74. Min, K.-B., Lee, K.-J., Park, J.-B. \& Min, J.-Y. Lead and cadmium levels and balance and vestibular dysfunction among adult participants in the National Health and Nutrition Examination Survey (NHANES) 1999-2004. Environ. Health Perspect. 120, 413-417 (2012).

75. Brauer, M. et al. Traffic-related air pollution and otitis media. Environ. Health Perspect. 114, 1414-1418 (2006).

76. MacIntyre, E. A. et al. Residential air pollution and otitis media during the first two years of life. Epidemiology 20, 81-89 (2011).

77. Gestro, M., Condemi, V., Bardi, L., Fantino, C. \& Solimene, U. Meteorological factors, air pollutants, and emergency department visits for otitis media: A time series study. Int. J. Biometeorol. 61, 1749-1764 (2017).

78. Rich, D. Q. et al. Association between changes in air pollution levels during the Beijing Olympics and biomarkers of inflammation and thrombosis in healthy young adults. JAMA 307, 2068-2078 (2012).

79. Myung, W. et al. Association between levels of high-sensitivity C-reactive protein and general psychological distress symptoms. JAMA Psychiatr. 73, 1199-1201 (2016).

80. Söderman, A. C. H., Möller, J., Bagger-Sjöbäck, D., Bergenius, J. \& Hallqvist, J. Stress as a trigger of attacks in Meniere’s disease. A case-crossover study. laryngoscope 114, 1843-1848 (2004).

81. Lim, Y.-H. et al. Air pollution and symptoms of depression in elderly adults. Environ. Health Perspect. 120, 1023-1028. https://doi. org/10.1289/ehp.1104100 (2012).

82. Szyszkowicz, M., Stieb, D. M. \& Rowe, B. H. Air pollution and daily ED visits for migraine and headache in Edmonton, Canada. Am. J. Emerg. Med. 27, 391-396. https://doi.org/10.1016/j.ajem.2008.03.013 (2009).

83. Townsend, C. \& Maynard, R. Effects on health of prolonged exposure to low concentrations of carbon monoxide. Occup. Environ. Med. 59, 708-711 (2002)

84. Nattero, G. \& Enrico, A. Outdoor pollution and headache. Headache J. Head Face Pain 36, 243-245 (1996).

85. Katsarkas, A. Hearing loss and vestibular dysfunction in Meniere's disease. Acta Otolaryngol. 116, 185-188. https://doi.org/10. 3109/00016489609137819 (1996)

86. Uneri, A. \& Polat, S. Vertigo, dizziness and imbalance in the elderly. J. Laryngol. Otol. 122, 466-469. https://doi.org/10.1017/s0022 215107000424 (2008).

87. Xiao, Q. et al. Pediatric emergency department visits and ambient Air pollution in the US State of Georgia: A case-crossover study. Environ. Health 15, 115 (2016).

88. Anderson, H. et al. Air pollution, pollens, and daily admissions for asthma in London 1987-92. Thorax 53, 842-848 (1998)

89. Hajat, S., Haines, A., Goubet, S., Atkinson, R. \& Anderson, H. Association of air pollution with daily GP consultations for asthma and other lower respiratory conditions in London. Thorax 54, 597-605 (1999).

90. Zemek, R., Szyszkowicz, M. \& Rowe, B. H. Air pollution and emergency department visits for otitis media: A case-crossover study in Edmonton, Canada. Environ. Health Perspect. 118, 1631-1636 (2010).

91. Fullman, N. et al. Measuring performance on the Healthcare Access and Quality Index for 195 countries and territories and selected subnational locations: A systematic analysis from the Global Burden of Disease Study 2016. Lancet 391, 2236-2271 (2018).

\section{Acknowledgements}

This research was supported by the Basic Science Research Program through the National Research Foundation of Korea (NRF) funded by the Ministry of Science, ICT \& Future Planning (NRF-2019R1A2C1089986).

\section{Author contributions}

Conception and design: M.K.P. Acquisition of data: J.Y.H., M.J.J. Formal analysis: J.Y.H., M.J.J. Methodology: J.Y.H., M.J.J., M.K.P. Project administration: M.K.P. Visualization: J.Y.H., M.J.J., D.H.L. Writing一original draft: D.H.L. Writing-review and editing: D.H.L., J.Y.H., M.J.J., M.W.S., J.H.L., S.H.O., M.K.P.

\section{Competing interests}

The authors declare no competing interests.

\section{Additional information}

Supplementary Information The online version contains supplementary material available at https:/doi.org/ 10.1038/s41598-021-92355-0.

Correspondence and requests for materials should be addressed to M.K.P.

Reprints and permissions information is available at www.nature.com/reprints.

Publisher's note Springer Nature remains neutral with regard to jurisdictional claims in published maps and institutional affiliations.

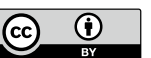

Open Access This article is licensed under a Creative Commons Attribution 4.0 International License, which permits use, sharing, adaptation, distribution and reproduction in any medium or format, as long as you give appropriate credit to the original author(s) and the source, provide a link to the Creative Commons licence, and indicate if changes were made. The images or other third party material in this article are included in the article's Creative Commons licence, unless indicated otherwise in a credit line to the material. If material is not included in the article's Creative Commons licence and your intended use is not permitted by statutory regulation or exceeds the permitted use, you will need to obtain permission directly from the copyright holder. To view a copy of this licence, visit http://creativecommons.org/licenses/by/4.0/.

(C) The Author(s) 2021 